Int. J. Dev. Biol. 54: 1061-1065 (2010)

doi: $10.1387 / \mathrm{ijdb} .103097 \mathrm{mt}$

\title{
Embryonic origin of human hematopoiesis
}

\author{
MANUELA TAVIAN *,1,2, KATIA BIASCH ${ }^{1}$, LIDIA SINKA ${ }^{2}$, JUDITH VALLET ${ }^{1}$ and BRUNO PÉAULT ${ }^{3}$ \\ 1 INSERM U682, University of Strasbourg, Strasbourg, France, \\ 2INSERM, U602, University Paris-Sud, France and \\ ${ }^{3}$ David Geffen School of Medicine at UCLA-Orthopaedic Hospital Research Center, Los Angeles, CA, USA
}

\begin{abstract}
Hematopoietic stem cells (HSC) are at the origin of the adult hematopoietic system. They give rise to all blood cells through a complex series of proliferation and differentiation events that occur throughout the lifespan of the individual. Because of their potential clinical importance in transplantation, recent research has focused on the developmental origins of embryonic HSC. During development in vertebrate embryos, two independent anatomical sites generate hematopoietic cells. The yolk sac is responsible for a first ephemeral hematopoiesis, characterized by the early appearance of hematopoietic progenitors with limited development ability that rapidly differentiate toward erythro-myeloid lineages. Self-renewing, multipotent adult-type HSC that also exhibit B and T lymphoid potentials emerge autonomously in the aorta/gonad/mesonephros (AGM) region inside the embryo. In this review, we provide a brief summary of recent developments regarding the origins of hematopoietic stem cells in the early human embryo. The recent discovery that angiotensin-converting enzyme (ACE) is a novel cell surface marker of human HSC is discussed in detail.
\end{abstract}

KEY WORDS: human embryo, stem cell, hematopoiesis, mesoderm, endothelium

\section{Introduction}

The hematopoietic system consists in a large array of differentiated blood cells including erythocytes and cells of the myeloid and lymphoid lineages. These mature blood cells have a limited lifespan and are continuously replaced by the proliferation and differentiation of a very small cohort of pluripotent hematopoietic stem cells (HSC). Indeed, HSC have the ability to replenish their own compartment (i.e., they demonstrate self renewal) and to differentiate into progenitor cells and mature blood cells of all hematopoietic lineages. In adult mammals, blood cells are generated primarily within the medullary cavity of some bones. It is generally considered that HSC encountered in the adult bone marrow arise by replication and amplification of a stock of HSC that emerged early in ontogenesis, when the bone marrow had not yet formed.

As in all other vertebrates, human hematopoiesis begins in the yolk sac (YS) and then takes place transitorily in the liver, before being definitively established in the thymus and bone marrow. Studies performed in other species, namely mouse and chicken, have indicated that all hematopoietic organs (liver, thymus and also the bone marrow) do not produce their own hematopoietic precursors but have to be colonized by extrinsic blood progenitor cells (Le Douarin et al., 1984; Moore and Owen, 1967). This pathway set the basis for the prevailing idea that the $\mathrm{YS}$ was the only site of de novo blood-cell generation from HSC (Moore and Metcalf, 1970). In contrast, experiments in birds later demonstrated that definitive hematopoiesis stems from precursors emerging in the embryo proper, localized in a region neighboring the dorsal aorta (reviewed in Dieterlen-Lievre, 1994). In mammals, evidence for an intraembryonic emergence of hematopoietic progenitors was obtained in mice and in the human embryo. In the mouse, the aorta-gonad-mesonephros (AGM) region, a territory homologous to that identified in birds, and its anlage, the paraaortic splanchnopleura (P-Sp), are endowed with hematopoietic potential (reviewed in Dzierzak and Speck, 2008). Indeed, cells expressing markers of hematopoietic progenitors are present in the dorsal aorta (reviewed in Cumano and Godin, 2007). We have participated in this discovery by identifying in the human embryo a dense population of HSC emerging in association with the ventral side of the aortic endothelium, between the $27^{\text {th }}$ and the

Abbreviations used in this paper: ACE, angiotensin-converting enzyme; AGM, aorta/gonad/mesonephros; HSC, hematopoietic stem cells; P-Sp, paraaortic splanchnopleura; YS, yolk sac.

\footnotetext{
*Address correspondence to: Manuela Tavian. INSERM U682, 3 avenue Molière, 67200 Strasbourg, France. e-mail: manuela.tavian@inserm.fr Tel: +33 388275 368. web: http://u682-inserm.u-strasbg.fr/projecteamMT.htm
}

Final author corrected PDF published online: 16 July 2010.

ISSN: Online 1696-3547, Print 0214-6282 
$40^{\text {th }}$ day of development (reviewed in Tavian and Peault, 2005a).

In the following review we will present an overview of advances in the field of human developmental hematopoiesis. In the first part, we show evidence for the independent generation of intraembryonic hematopoietic precursors. Second, through the analysis of the expression of ACE, a novel marker of HSC, we point to the very origin of human embryonic hematopoiesis.

\section{The embryo proper as a site of blood cell generation}

The first evidence for the existence of an intrinsic blood cell activity inside the human embryo was reported by the group of $L$. Coulombel using colony assays established with CD34+ cells purified from extraembryonic yolk sacs and intraembryonic tissues (Huyhn et al., 1995). Under these conditions non-erythroid progenitors were predominantly found in the embryo, whereas erythroid progenitors were more equally distributed. In particular, a higher proportion of non-erythroid progenitors (including highproliferative potential cells, HPP-CFC) was present among cells remaining after the liver has been removed, indicating that intraembryonic hematopoietic activity was not predominantly hepatic (Huyhn et al., 1995).

The presence inside the embryonic compartment of progenitors presenting a HSC phenotype was corroborated by our group which identified a dense population of CD34+ blood cells adhering to the ventral side of the aortic endothelium (Fig. 1A) (Tavian etal., 1996). This cell population displayed a cell-surface and molecular phenotype typifying primitive hematopoietic progenitors (CD45 ${ }^{+}$, $\mathrm{CD}^{+}{ }^{+}, \mathrm{CD}^{2} 1^{+}, \mathrm{CD} 38^{-}$, negative for lineage markers, GATA-2 ${ }^{+}$, GATA-3 ${ }^{+}, \mathrm{c}-\mathrm{myb}+, \mathrm{SCL} / \mathrm{TAL} 1^{+}, \mathrm{c}^{-\mathrm{kit}^{+}, \text {flk-1/KDR}}{ }^{+}$) (Labastie et al., 1998; Tavian et al., 1996). Hematopoietic cell clusters appeared precisely in the embryo between the 27th and 40th days of development, which corresponded to 2-3 days before hepatic colonization by CD34+ progenitors (Tavian etal., 1999). Therefore, thousands of hematopoietic cells were clustered on the endothelium of the dorsal aorta and vitelline artery indicating the existence in this organ of a localized microenvironment which could regulate cell fate, both spatially and temporally. A number of circumstantial observations have been already made in this respect such as the presence of an accumulation of smooth actin-positive cells and the high expression of tenascin- $C$, indicating local changes in the mesoderm underneath the clusters (Marshall et al., 1999; also reviewed in Tavian and Peault, 2005b).

\section{The embryo is hemogenic even before the aorta forms}

The possibility that these cells were derived from YS blood islands, rather than generated locally within the embryo proper, has been ruled out by investigations performed at earlier developmental stages, when blood does not yet circulate between the YS and the embryo.

The developmental potential of human embryonic and YS-derived cells, in terms of blood cell lineages, was analyzed in a novel multistep in vitro assay (for experimental details, see Tavian and Peault, 2005c). Under these conditions we have assayed each compartment before and after the 21-day stage, which marks the onset of blood circulation. Successively the splanchnopleura (the presumptive dorsal aorta), the paraaortic splanchnopleura, and the aorta itself were dissected out and cultured. Matching YSs were analyzed under the same conditions in all experiments. From 27 to 40 days of gestation, when intravascular HSC clusters were present, the aorta expectedly established long-term hematopoietic cell cultures. The same potential, however, was already observed within the 19-day splanchnopleura (i.e., 3 days before the onset of blood circulation and 1 week before the detection of recognizable HSC clusters in the aorta). In conclusion, hematopoietic progenitors emerge autonomously in the YS but also within the human embryo proper, from the splanchnopleural mesoderm (Tavian et al., 2001).

\section{The embryo but not the yolk sac generates multipotent lymphomyeloid stem cells}

Cells derived from these two independent blood stem cell generation sites, the intraembryonic splanchnopleura and YS, were cultured on the MS-5 murine stroma cell line, which permits the long-term development of both myeloid and lymphoid human progenitors. In these settings, we showed that the yolk sac only generates progenitor cells with limited development ability, whereas progenitors emerging autonomously in the presumptive aortic territory are endowed with multilineage lympho-myeloid potential (Tavian et al., 2001). Therefore, the first and only multipotent, myelolymphoid stem cells are generated in the splanchnopleura, within the embryo proper, and are physically present within trunk arteries during the fifth week of development. These cells were therefore suggested to be at the origin of definitive hematopoiesis (Tavian et al., 2001).
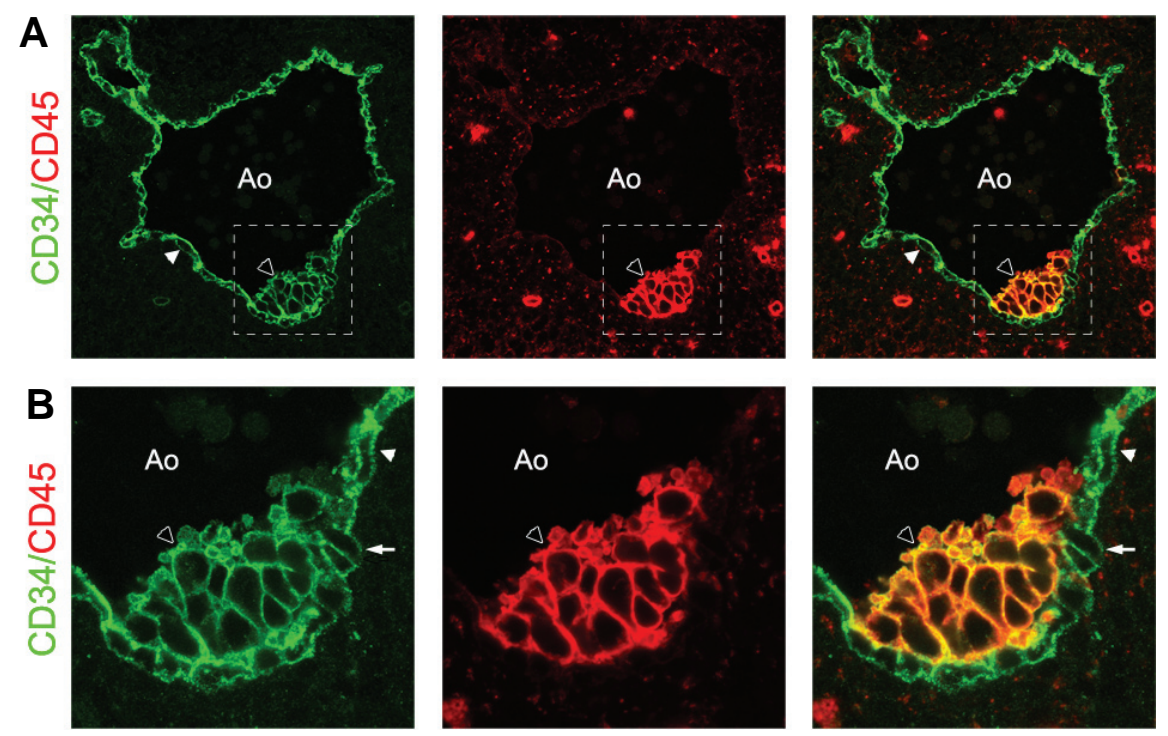

Fig. 1. Hematopoietic stem cell clusters inside human embryonic arteries. (A) Cross sections of a 34-day human aorta (Ao) stained with the anti-CD34 (green) and anti-CD45 (red) antibodies. Arrows indicate the clusters of hematopoietic stem cells adhering to the ventral aspect of the aortic endothelium (white arrowhead). (B) Confocal images at higher magnification of the region included in the dotted white line in panel A show the changed morphology of endothelial cells underlying hematopoietic clustered progenitors (arrow). 


\section{Intraembryonic hematopoiesis: what is the origin of HSC?}

Despite the progress made in the last decade in the understanding of hematopoietic stem cell development during embryogenesis, the cellular identity of the population responsible for this early activity still remains unknown. Several hypotheses have been proposed.

\section{Hemangioblasts or «hemogenic» endothelial cells?}

Since in the primitive sites of blood cell emergence - the yolk sac and the aorta - HSC stem in close physical association with endothelial cells, the current models for hematopoietic cell generation emphasize a direct ontogenic link between the two lineages.

In the yolk sac, the blood islands are generated by mesodermal cell aggregates, which differentiate into both hematopoietic and endothelial cells. The simultaneous appearance of these two lineages suggested the existence of a common ancestral precursor for endothelial and hematopoietic cells - the hemangioblast (Murray, 1932). Further and more recent supporting evidence for a lineage relationship includes the observation that the two cell types share a number of surface markers and that null mutations in a number of genes, such as flk1 (Shalaby et al., 1997), affect both cell lineages. In contrast to the yolk sac, hematopoietic activity inside the embryo occurs when endothelial cells are already present, which makes it difficult to link the emergence of intraembryonic blood cells to a population of hemangioblasts. These observations set the basis for the idea that endothelial cells themselves could play a major role in blood cell development. The existence of a "hemogenic" endothelium which can give rise to hematopoietic cells, first suggested in 1920 by Sabin (Sabin, 1920), has been recently demonstrated for avian and mouse intraembryonic hematopoiesis (de Bruijn et al., 2002; Jaffredo et al., 1998; Nishikawa et al., 1998; Pouget et al., 2006). In agreement with these reports, we have observed that, also in the human embryo, endothelial cells located on the ventral site of the dorsal aorta present a morphology distinct from those the endothelium of the dorsal site. On the ventral aspect site, the normal layer of endothelial cells lining the lumen of the aorta is disrupted and replaced by a less organized population of rounded cells (Fig. 1B). Prompted by these observations, we sorted by flow cytometry vascular endothelial cells from embryonic and fetal human bloodforming tissues and analyzed their hematopoietic ability by culture over a layer of MS- 5 stromal cells. In this context, endothelial cells sorted from the human embryonic aorta between 27 and 40 days of development - when HSC are present in this region - gave rise to vigorous hematopoiesis. The frequency of hematogenous endothelial cells in the AGM, at a given stage of human ontogeny, was directly correlated with the hematopoietic activity of this territory. Conversely, no hematopoietic activity was detected in cultured endothelial cells sorted from the AGM region after day 40 , when $\mathrm{HSC}$ are no longer present in the lumen of the aorta (Oberlin et al., 2002).

\section{Alternative models: mesodermal precursors?}

The experiments described above suggested that ventral endothelial cells in human intraembryonic arteries divide and differentiate into blood cell progenitors at the origin of definitive hematopoiesis (Oberlin et al., 2002). However, endothelial CD $34^{+}$CD 45 cells sorted from the human splanchnopleura as late as days 24-26 of gestation - when a hemogenic ability exists in vitro but the aortic HSC clusters are not yet present - yielded no blood cell progeny in culture. Conversely, the blood-forming potential in these early embryos was entirely confined within the CD34-CD45 ${ }^{-}$cell subset (MT, personal observations). This posits the presence in the splanchnopleural mesoderm of CD34- precursors possibly committed toward a hematopoietic fate, which would migrate through the peri-aortic mesenchyme and be at the origin of the HSC associated with the vascular endothelium from day 27 of development (Tavian and Peault, 2005c).

An alternative to the hemogenic endothelium has also been suggested in the mouse embryo, based on the presence of structures potentially involved in intraembryonic HSC generation - the subaortic patches, SAPs -, located below the aortic floor (Bertrand et al., 2005; Manaia et al., 2000). The phenotype of the cells included in SAPs suggests that the hemogenic ability is restricted to precursors with a non-endothelial antigen expression profile (Bertrand et al., 2005; Manaia et al., 2000). According to this model, HSC would be generated within SAPs, migrate toward the aortic floor and reach the blood flow to colonize the fetal liver. This transition across the ventral endothelium of the aorta could justify the presence of a hemogenic endothelium which is detected only at certain stages of development when the HSC are present in the AGM (Oberlin etal., 2002; also reviewed in Cumano and Godin, 2007).

\section{BB9/ACE (angiotensin-converting enzyme), a novel marker of HSC, can identify pre-hematopoietic precur- sors inside the human embryo}

BB9 is a monoclonal antibody $(\mathrm{mAb})$ initially described to react in adult human bone marrow with stromal cells and with a subpopulation of $\mathrm{CD}_{3} 4^{+}$cells presenting the phenotypic characteristics of immature progenitors, namely low to undetectable levels of CD38 and coexpression of CD90 and CD133 (Ramshaw et al., 2001).

In a recent study we have shown that $\mathrm{BB} 9$, which turned out to recognize the somatic isoform of the angiotensin converting
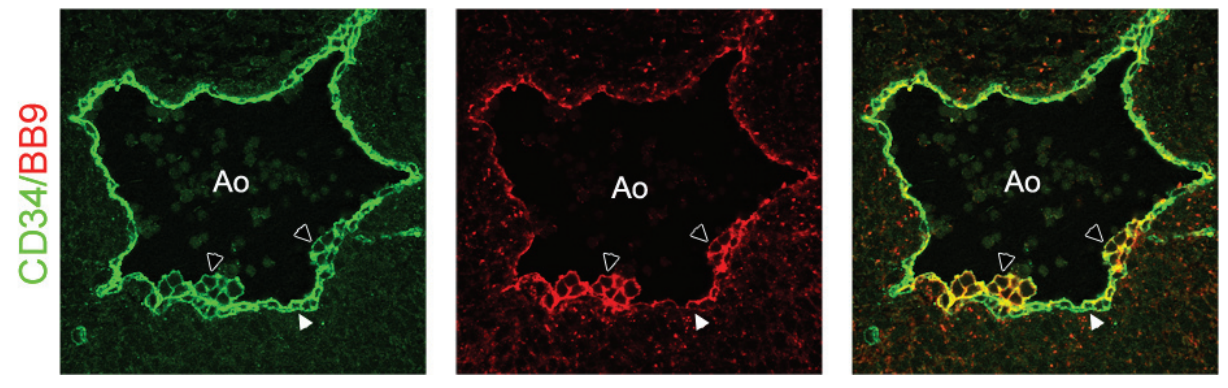

Fig. 2. Expression of BB9/angiotensin-converting-enzyme (BB9/ACE) in the human embryo. Cross sections through the dorsal aorta $(A O)$ in a 34-day embryo. BB9/ACE is expressed by hematopoetic $\mathrm{CD} 34^{+} \mathrm{CD} 45^{+}$cell clusters associated with the endothelium on the ventral site of the aorta (arrowheads), as well as by underlying endothelial CD34+ cells (white arrowheads). 
enzyme (ACE/CD143), exhibits reactivity with primitive hematopoietic cells at all stages of hematopoietic ontogeny including in the umbilical cord blood (UCB) and fetal liver. Transplantations into NOD/SCID mice demonstrated that CD34+BB9 ${ }^{+}$cells from UCB, but not CD34+ cells lacking expression of BB9, sustained multilineage human hematopoietic cell engraftment and, therefore, clearly established BB9/ACE as a bona fide marker of human HSC (Jokubaitis et al., 2008).

In the attempt to track the earliest forerunners of intraembryonic blood forming activity, we have recently examined BB9 expression in earlier human embryos. We observed that ACE also identifies hematopoietic clusters (Fig. 2) emerging on the ventral aortic endothelium at 4-5-weeks, as well as the neighboring endothelial cells (Jokubaitis et al., 2008). In addition, BB9 identified a few cells scattered among the subaortic mesoderm, on which no colocalization of CD34 or CD45 was observed, suggesting the angiohematopoietic potential of BB9-positive mesodermal progenitors (Jokubaitis et al., 2008). An analysis conducted at even earlier stages of human development is consistent with this hypothesis (Sinka et al., submitted). Indeed, starting from day 19 until 26 days of gestation, when HSC clusters are not yet developed within the vascular aortic wall, BB9/ACE expression marks rare $\mathrm{CD}^{-} 4^{-} \mathrm{CD} 4^{-}$cells in the embryo proper, scattered in the hemogenic portion of the P-Sp. Along these lines, results obtained by culturing cells sorted from 24- to 26-day human embryos indicate that $\mathrm{BB9}^{+}$, but not $\mathrm{BB} 9$ cells, are endowed with hematopoietic ability (Sinka et al. submitted). In accord with these observations, a recent study of human embryonic stem cells (hESC) has shown that hESC derived $\mathrm{ACE}^{+} \mathrm{CD} 45^{-} \mathrm{CD} 34^{+/-}$cells are common yolk sac-like progenitors for not only endothelium, but also both primitive and definitive human lympho-hematopoietic stem cells (Zambidis et al., 2008).

\section{Conclusions}

Altogether, these findings put forth the concept that BB9/ACE, already accepted as a novel marker for very primitive HSC, could also mark pre-hematopoietic cells inside the human mesoderm, which would imply that definitive hematopoiesis arises inside the human embryo from intrinsic mesodermal stem cells identifiable with the BB9 antibody, and thereby expressing ACE.

This pattern supports the hypothesis of the existence of a $\mathrm{BB}^{+} \mathrm{CD} 34^{-} \mathrm{CD} 45^{-}$hemangioblastic precursor cell that migrates from the P-Sp toward the ventral aorta, to give rise to $B B{ }^{+} \mathrm{CD} 34^{+} \mathrm{CD} 45^{+}$hematopoietic progenitors and underlying BB9 ${ }^{+} \mathrm{CD} 34{ }^{+} \mathrm{CD} 45^{-}$endothelial cells. In accord with such an interpretation, a recent work has shown, through lineage tracing approaches, that the endothelium lining the ventral wall of the aorta is responsible for HSC emergence in the mouse AGM and that this hemogenic endothelium is derived from a transient mesenchymal population (Zovein et al., 2008).

\section{Acknowledgements}

Work in our laboratory is supported in part by grants from INSERM (Avenir Project), and in part by grants from the Association pour la Recherche contre le Cancer ( $n^{\circ} 4814$ ) and from the Ligue contrele Cancer to MT. $L S$ was the recipient of fellowships from the French MENRT (Ministère de l'Education Nationale de la Recherche et de la Technologie) from the Association Nouvelle Recherche Biomédicale and from the Association pour la Recherche contre le Cancer. $K B$ is a recipient of an
INSERM fellowship (INSERM-région Alsace). We thank Guy Roussel for excellent assistance with confocal microscopy.

\section{References}

BERTRAND, J.Y., GIROUX, S., GOLUB, R., KLAINE, M., JALIL, A., BOUCONTET, L., GODIN, I. and CUMANO, A. (2005). Characterization of purified intraembryonic hematopoietic stem cells as a tool to define their site of origin. Proc Nat/ Acad Sci USA 102: 134-139.

CUMANO, A. and GODIN, I. (2007). Ontogeny of the hematopoietic system. Annu Rev Immuno/25: 745-785.

DE BRUIJN, M.F., MA, X., ROBIN, C., OTTERSBACH, K., SANCHEZ, M.J. and DZIERZAK, E. (2002). Hematopoietic stem cells localize to the endothelial cell layer in the midgestation mouse aorta. Immunity 16: 673-683.

DIETERLEN-LIEVRE, F. (1994). Hemopoiesis during avian ontogeny. Poultry Sci. Rev. 5: 273-305

DZIERZAK, E. and SPECK, N.A. (2008). Of lineage and legacy: the development of mammalian hematopoietic stem cells. Nat Immuno/9: 129-136.

HUYHN, A., DOMMERGUES, M., IZAC, B., CROISILlE, L., KATZ, A., VAINCHENKER, W. and COULOMBEL, L. (1995). Characterization of hematopoietic progenitors from human yolk sacs and embryos. Blood86: 4474-4485.

JAFFREDO, T., GAUTIER, R., EICHMANN, A. and DIETERLEN-LIEVRE, F. (1998). Intraaortic hemopoietic cells are derived from endothelial cells during ontogeny. Development 125: 4575-4583.

JOKUBAITIS, V.J., SINKA, L., DRIESSEN, R., WHITTY, G., HAYLOCK, D.N. BERTONCELLO, I., SMITH, I., PEAULT, B., TAVIAN, M. and SIMMONS, P.J. (2008). Angiotensin-converting enzyme (CD143) marks hematopoietic stem cells in human embryonic, fetal, and adult hematopoietic tissues. Blood 111 : 4055-4063.

LABASTIE, M.C., CORTÉS, F., ROMÉO, P.H., DULAC, C. and PÉAULT, B. (1998). Molecular identity of hematopoietic precursor cells emerging in the human embryo. Blood 92: 3624-3635

LE DOUARIN, N.M., DIETERLEN-LIEVRE, F. and OLIVER, P.D. (1984). Ontogeny of primary lymphoid organs and lymphoid stem cells. Am J Anat 170: 261-299.

MANAIA, A., LEMARCHANDEL, V., KLAINE, M., MAX-AUDIT, I., ROMEO, P., DIETERLEN-LIEVRE, F. and GODIN, I. (2000). Lmo2 and GATA-3 associated expression in intraembryonic hemogenic sites. Development 127: 643-653.

MARSHALL, C.J., MOORE, R.L., THOROGOOD, P., BRICKELL, P.M., KINNON, C. and THRASHER, A.J. (1999). Detailed characterization of the human aortagonad-mesonephros region reveals morphological polarity resembling a hematopoietic stromal layer. Dev Dyn 215: 139-147.

MOORE, M.A. and METCALF, D. (1970). Ontogeny of the haemopoietic system yolk sac origin of in vivoand in vitrocolony forming cells in the developing mouse embryo. British Journal of Haematology 18: 279-296.

MOORE, M.A.S. and OWEN, J.J.T. (1967). Stem cell migration in developing myeloid and lymphoid systems. Lancet2: 658-659.

MURRAY, P.D.F. (1932). The development «in vitros of blood of the early chick embryo. Proc. Roy. Soc. London Serie B111: 497-521.

NISHIKAWA, S.I., NISHIKAWA, S., KAWAMOTO, H., YOSHIDA, H., KIZUMOTO, M., KATAOKA, $\mathrm{H}$. and KATSURA, Y. (1998). In vitro generation of lymphohematopoietic cells from endothelial cells purified from murine embryos. Immunity 8: 761-769.

OBERLIN, E., TAVIAN, M., BLAZSEK, I. and PEAULT, B. (2002). Blood-forming potential of vascular endothelium in the human embryo. Development 129: 4147-4157.

POUGET, C., GAUtiER, R., TEILlET, M.A. and JAFFREDO, T. (2006). Somitederived cells replace ventral aortic hemangioblasts and provide aortic smooth muscle cells of the trunk. Development 133: 1013-1022.

RAMSHAW, H.S., HAYLOCK, D., SWART, B., GRONTHOS, S., HORSFALL, M.J., NIUTTA, S. and SIMMONS, P.J. (2001). Monoclonal antibody BB9 raised against bone marrow stromal cells identifies a cell-surface glycoprotein expressed by primitive human hemopoietic progenitors. Exp Hemato/ 29: 981 992.

SABIN, F.R. (1920). Studies on the origin of blood vessels and of red blood corpuscles as seen in the living blastoderm of chicks during the second day of 
incubation. Carnegie Inst. Wash. Pub. n०272, Contrib. Embryol. 9: 214-262.

SHALABY, F., HO, J., STANFORD, W.L., FISCHER, K.D., SCHUH, A.C., SCHWARTZ, L., BERNSTEIN, A. and ROSSANT, J. (1997). A requirement for Flk1 in primitive and definitive hematopoiesis and vasculogenesis. Cel/89: 981-990.

TAVIAN, M., COULOMBEL, L., LUTON, D., CLEMENTE, H.S., DIETERLENLIEVRE, F. and PEAULT, B. (1996). Aorta-associated CD34+ hematopoietic cells in the early human embryo. Blood 87: 67-72.

TAVIAN, M., HALLAIS, M.F. and PEAULT, B. (1999). Emergence of intraembryonic hematopoietic precursors in the pre-liver human embryo. Development 126: 793-803.

TAVIAN, M. and PEAULT, B. (2005a). Embryonic development of the human hematopoietic system. Int J Dev Bio/49: 243-250.

TAVIAN, M. and PEAULT, B. (2005b). The changing cellular environments of hematopoiesis in human development in utero. Exp Hemato/33: 1062-1069.
TAVIAN, M. and PEAULT, B. (2005c). Analysis of hematopoietic development during human embryonic ontogenesis. Methods Mol Med 105: 413-424.

TAVIAN, M., ROBIN, C., COULOMBEL, L. and PEAULT, B. (2001). The human embryo, but not its yolk sac, generates lympho-myeloid stem cells: mapping multipotent hematopoietic cell fate in intraembryonic mesoderm. Immunity 15 487-495.

ZAMBIDIS, E.T., PARK, T.S., YU, W., TAM, A., LEVINE, M., YUAN, X., PRYZHKOVA, M. and PEAULT, B. (2008). Expression of angiotensin-converting enzyme (CD143) identifies and regulates primitive hemangioblasts derived from human pluripotent stem cells. Blood 112: 3601-3614.

ZOVEIN, A.C., HOFMANN, J.J., LYNCH, M., FRENCH, W.J., TURLO, K.A., YANG, Y., BECKER, M.S., ZANETTA, L., DEJANA, E., GASSON, J.C. et al. (2008). Fate tracing reveals the endothelial origin of hematopoietic stem cells. Cell Stem Cel/3: 625-636.

\section{Further Related Reading, published previously in the Int. J. Dev. Biol.}

See our recent Special Issue Placenta edited by Joan S. Hunt and Kent L. Thornburg at: http://www.ijdb.ehu.es/web/contents.php?vol=54\&issue=2-3

Novel roles for Notch, Wnt and Hedgehog in hematopoesis derived from human pluripotent stem cells

Chantal Cerdan and Mickie Bhatia

Int. J. Dev. Biol. (doi: 10.1387/ijdb.103067cc)

Epiblast-derived stem cells in embryonic and adult tissues

Maria P. De-Miguel, Francisco Arnalich-Montiel, Pilar Lopez-Iglesias, Alejandro BlazquezMartinez and Manuel Nistal

Int. J. Dev. Biol. (2009) 53: 1529-1540

Multilineage hematopoietic progenitor activity generated autonomously in the mouse yolk sac: analysis using angiogenesis-defective embryos

Christine Rampon and Philippe Huber

Int. J. Dev. Biol. (2003) 47: 273-280

Tracing the hemangioblast during embryogenesis: developmental relationships between endothelial and hematopoietic cells

Thierry Jaffredo, Karine Bollerot, Daisuke Sugiyama, Rodolphe Gautier and Cécile Drevon Int. J. Dev. Biol. (2005) 49: 269-277

Of birds and mice: hematopoietic stem cell development Isabelle Godin and Ana Cumano Int. J. Dev. Biol. (2005) 49: 251-257

Embryonic development of the human hematopoietic system Manuela Tavian and Bruno Péault Int. J. Dev. Biol. (2005) 49: 243-250

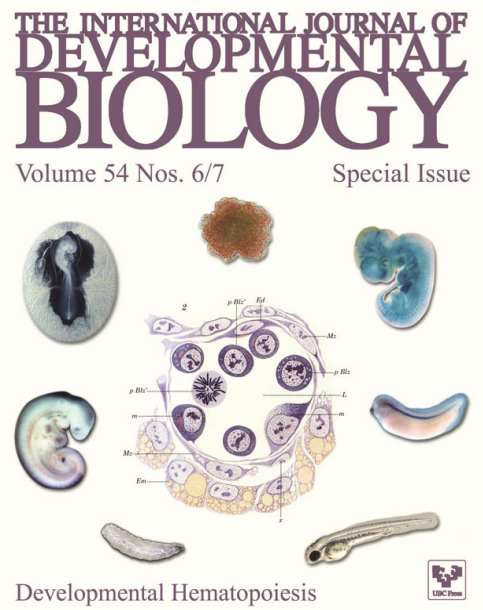

5 yr ISI Impact Factor $(2009)=3.253$

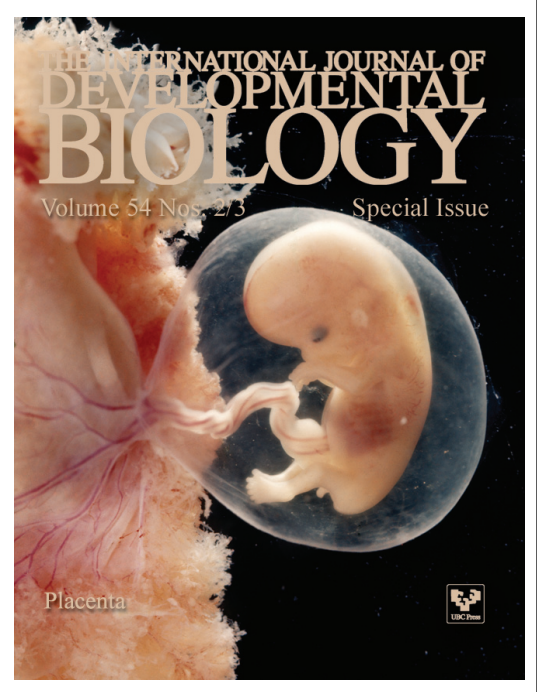

